\title{
Tissue-type plasminogen activator suppresses activated stellate cells through low-density lipoprotein receptor-related protein 1
}

\author{
Liang-I Kang ${ }^{1}$, Kumiko Isse ${ }^{1}$, Kelly Koral ${ }^{1}$, William C Bowen', Selen Muratoglu²,3, Dudley K Strickland ${ }^{2,3,4}$, \\ George K Michalopoulos ${ }^{1}$ and Wendy M Mars $^{1}$
}

Hepatic stellate cell (HSC) activation and trans-differentiation into myofibroblast (MFB)-like cells is key for fibrogenesis after liver injury and a potential therapeutic target. Recent studies demonstrated that low-density lipoprotein receptorrelated protein 1 (LRP1)-dependent signaling by tissue-type plasminogen activator (t-PA) is a pro-fibrotic regulator of the MFB phenotype in kidney. This study investigated whether LRP1 signaling by t-PA is also relevant to HSC activation following injury. Primary and immortalized rat HSCs were treated with t-PA and assayed by western blot, MTT, and TUNEL. In vitro results were then verified using an in vivo, acute carbon tetrachloride $\left(\mathrm{CCl}_{4}\right)$ injury model that examined the phenotype and recovery kinetics of MFBs from wild-type animals vs mice with a global (t-PA) or HSC-targeted (LRP1) deletion. In vitro, in contrast to kidney MFBs, exogenous, proteolytically inactive t-PA suppressed, rather than induced, activation markers in HSCs following phosphorylation of LRP1. This process was mediated by LRP1 as inhibition of t-PA binding to LRP1 blocked the effects of t-PA. In vivo, following acute injury, phosphorylation of LRP1 on activated HSCs occurred immediately prior to their disappearance. Mice lacking t-PA or LRP1 retained higher densities of activated HSCs for a longer time period compared with control mice after injury cessation. Hence, t-PA, an FDA-approved drug, contributes to the suppression of activated HSCs following injury repair via signaling through LRP1. This renders t-PA a potential target for exploitation in treating patients with fibrosis.

Laboratory Investigation (2015) 95, 1117-1129; doi:10.1038/labinvest.2015.94; published online 3 August 2015

Liver cirrhosis is a growing global health concern due to an increased prevalence of chronic liver diseases, including viral hepatitis and non-alcoholic fatty-liver disease. Regardless of etiology, chronic parenchymal injury leads to accumulation of scar tissue and organ dysfunction through a highly orchestrated process centered on the emergence of a de novo population of myofibroblast (MFB)-like cells. Hepatic stellate cells (HSCs) are considered one of the major sources of matrix-depositing MFB-like cells in chronic liver injury. In response to inflammatory cytokines and growth factors, HSCs become activated and exhibit increased proliferative, migratory, contractile, and fibrogenic phenotypes. ${ }^{1}$ Understanding the factors that regulate HSC activation and trans-differentiation is the key to designing effective therapies.

The plasminogen activators (PAs) are multi-functional serine proteases involved in fibrinolysis, cellular migration, ${ }^{2}$ growth factor activation, ${ }^{3}$ and hepatic repair. ${ }^{4,5}$ Loss of PAs delays liver regeneration after acute injury; this has been largely attributed to sustained fibrin deposition and loss of growth factor and matrix metalloproteinase activation. ${ }^{4}$ However, the roles of PA in chronic liver injury have been ambiguous ${ }^{6,7}$ possibly due to their pleiotropic functions on multiple cell types.

Emerging literature indicates that the biological effects of PAs in select systems are not limited to their proteolytic function. In fact, signaling functions may be equally, if not more, important to clearly understand their biological roles. In particular, the tissue-type PA (t-PA) is a key endogenous signaling molecule in injury and disease. One prominent $\mathrm{t}-\mathrm{PA}$ signaling receptor is LRP1 (low-density lipoprotein receptorrelated protein 1). LRP1 is a multi-ligand receptor often associated with protease-inhibitor complex and growth factor clearance; however, following ligand binding it can signal to promote cellular migration, differentiation, and changes in viability or proliferation. ${ }^{8}$

Recent studies involving kidney fibroblasts have defined a role for LRP1 in modulating tissue fibrosis and the MFB phenotype. ${ }^{9}$ As HSCs are now known to express LRP1, ${ }^{10,11}$ and little is known about the role of LRP1 in HSCs during

${ }^{1}$ Department of Pathology, University of Pittsburgh School of Medicine, Pittsburgh, PA, USA; ${ }^{2}$ Center for Vascular and Inflammatory Diseases, University of Maryland School of Medicine, Baltimore, MD, USA; ${ }^{3}$ Department of Physiology, University of Maryland School of Medicine, Baltimore, MD, USA and ${ }^{4}$ Department of Surgery, University of Maryland School of Medicine, Baltimore, MD, USA

Correspondence: Dr WM Mars, PhD, Department of Pathology, University of Pittsburgh School of Medicine, S407 Biomedical Science Tower, 200 Lothrop Street, Pittsburgh, PA 15261, USA.

E-mail: wmars@pitt.edu

Received 8 September 2014; revised 28 May 2015; accepted 20 June 2015 
liver injury and regeneration, this study sought to establish whether t-PA affects fibrosis through LRP1 in HSCs. We anticipated a pro-fibrotic response, similar to kidney; however, here, we instead present data supporting an antifibrotic role for t-PA in liver, identifying it as a potential therapeutic for treating fibrosis.

\section{MATERIALS AND METHODS}

\section{Reagents and Antibodies}

Recombinant single-chain (American Diagnostica, Stanford, CT, USA; Molecular Innovations, Novi, MI, USA) or an inhibitor-treated, non-proteolytic form of human t-PA (FPRCK-TPA, Molecular Innovations) was used for cellculture experiments. FPRCK-TPA is tested to have zero enzymatic activity by functional assay (personal communication with the company). Antibodies used for immunohistolabeling and Western blotting include: $\alpha$-SMA (Clone 1A4; Dako, Carpinteria, CA, USA; Sigma-Aldrich, St Louis, MO, USA), p-LRP1 (Santa Cruz Biotechology, Santa Cruz, CA, USA), LRP1 (Clone 11H4; ATCC, Manassas, VA, USA; \#3501, American Diagnostica), Collagen I (Abcam, Cambridge, MA), fibrinogen (Molecular Innovations), p-Akt (Thr308) and total Akt (both Cell Signaling Technology, Danvers, MA, USA), p-ERK1/2 and total ERK1/2 (Cell Signaling Technology). The PI3K pathway inhibitor LY294002 was from Cell Signaling Technology. Human RAP was prepared as previously described. ${ }^{12}$

\section{Rat HSC Isolation and Cell Culture}

Male Fischer 344 rats (Charles River, Wilmington, MA, USA) $\geq 200 \mathrm{~g}$ in weight were used to isolate primary HSCs via an adaptation from Riccalton-Banks, et al. ${ }^{13}$ Briefly, liver cells were dissociated using an in situ two-step collagenaseperfusion method. ${ }^{14,15}$ After low-gravity centrifugation of total liver cell suspension to pellet hepatocytes, nonparenchymal cells (NPC) were isolated from supernatants. The NPC fraction was washed once in complete medium (Dulbecco's Modified Eagle Medium $+10 \%$ fetal bovine serum $+0.1 \%$ gentamicin solution) and plated on uncoated six-well tissue-culture plates. Cells were maintained in a humidified incubator at $37^{\circ} \mathrm{C}$ with $5 \% \mathrm{CO}_{2}$. Complete medium was replaced $24 \mathrm{~h}$ post-plating. At $48 \mathrm{~h}$ post-plating, cells were serum-starved for $24 \mathrm{~h}$ before treatments. HSC cultures were minimally $80-85 \%$ pure. Rat HSC-T6 and human LX-2 HSC cell lines (Dr Scott Friedman, Mt. Sinai School of Medicine, New York, NY, USA) were maintained in the same medium as primary HSCs. For experiments, HSC-T6 cells were seeded at $3 \times 10^{5}$ cells $/ \mathrm{ml}$, incubated overnight and then serumstarved for $24 \mathrm{~h}$ prior to treatment. LX-2 cells were seeded at $1 \times 10^{5}$ cells $/ \mathrm{ml}$ and grown to $\sim 60 \%$ confluence prior to serum starvation and subsequent treatment. NRK-49F cells (ATCC) were cultured in Dulbecco's modified Eagle's medium:Ham's F12 (1:1) supplemented with 5\% FBS until $\sim 70 \%$ confluent, then serum-starved $24 \mathrm{~h}$ prior to treatments as indicated. All experiments were performed in serum-free conditions at $37^{\circ} \mathrm{C}$ in a humidified incubator. All experiments were performed in replicate (two or more times), using pooled samples to obtain sufficient protein or RNA. Actual $n$ for each replicate experiment performed is indicated in the legend.

\section{MTT Assay}

HSC-T6 cells were seeded at $3 \times 10^{5}$ cells $/ \mathrm{ml}$ and incubated overnight in complete medium. After washing with serumfree medium, cells were treated with vehicle control or t-PA $(10 \mathrm{nM})$ for $48 \mathrm{~h}$ serum-free. The MTT-based in vitro toxicology assay kit (Sigma-Aldrich) was used according to manufacturer instructions.

\section{TUNEL Assay}

HSC-T6 cells were seeded and treated as described for the MTT assay. After $48 \mathrm{~h}$, cells were fixed in $1 \%$ paraformaldehyde and labeled as indicated using the ApopTag Peroxidiase In Situ Apoptosis Detection Kit (Millipore, Temecula, CA, USA). A blinded team member assessed staining. Minimally, 10 low-powered images $(\times 100$ magnification) were quantified for each condition.

\section{SDS-PAGE and Western Blot}

Cell cultures were collected in lysis buffer $(10 \mathrm{mM}$ Tris buffer with $1 \%$ sodium dodecyl sulfate and protease/phosphatase inhibitor cocktail, defined as follows: Sigma-Aldrich catalog numbers: P8340, P2714, P2850, and P5726 (at recommended dilutions), AEBSF $(50 \mu \mathrm{g} / \mathrm{ml})$, and sodium amiloride $(1 \mathrm{mmol} / \mathrm{l})$ and analyzed by western blotting as previously described. ${ }^{16}$ Briefly, equal amounts of protein $(\sim 30 \mu \mathrm{g})$ from each sample was mixed with loading buffer with or without $100 \mathrm{mmol} / \mathrm{l}$ dithiothreitol, heated to $65^{\circ} \mathrm{C}$ for $15 \mathrm{~min}$, resolved by electrophoresis on 8 or $10 \%$ SDS-polyacrylamide gels, and transferred to polyvinylidene difluoride membranes for western blot analyses. Membranes were blocked in 5\% milk or fish gelatin in Tris-buffered saline +Tween, followed by incubation with primary antibody in 5\% blocking buffer. Horseradish peroxidase-conjugated secondary antibodies (Jackson ImmunoResearch Laboratories, West Grove, PA, USA) were used at a concentration of 1:50 000 . Blots were developed using enhanced chemiluminescence substrate (Pierce, Rockford, IL, USA) and visualized on X-ray film. Loading equivalence was assessed from densitometry of scanned images of Ponceau S $(0.2 \%$ solution $)$ staining performed immediately after transfer of protein onto the polyvinylidene difluoride membranes (see Statistical Analysis section for more detail). Protein concentration of samples was assessed by the bicinchoninic acid assay (Thermo Fisher Scientific, Rockford, IL, USA). Primary antibody concentrations used were as follows: $\alpha$-SMA (1:500-1:2000), p-LRP1 (1:500), LRP1 (1:1000-1:2000), PDGFR $\beta$ (1:500), p-Akt (1:1000) and total Akt (1:1000), p-ERK1/2 (1:1000), and total ERK1/2 (1:1000). 


\section{Immunoprecipitation}

HSC-T6 cells were treated with vehicle control or t-PA for $1 \mathrm{~min}$ and lysed in ice-cold CHAPS buffer (10 mM CHAPS, $20 \mathrm{mM}$ HEPES ( $\mathrm{pH}$ 7.4), $150 \mathrm{mM} \mathrm{NaCl}, 2 \mathrm{mM} \mathrm{CaCl}{ }_{2}$ ) supplemented with a phosphatase and protease inhibitor cocktail, as described above (Sigma-Aldrich). To obtain sufficient protein, multiple wells were pooled for these experiments.

One hundred micrograms of lysate from each treatment were incubated with the monoclonal antibody against LRP1 (11H4) or IgG control at $4{ }^{\circ} \mathrm{C}$ overnight with rotation. Protein A/G PLUS agarose beads (Santa Cruz Biotechnology) were added to the lysates and incubated at $4{ }^{\circ} \mathrm{C}$ for $3 \mathrm{~h}$. The beads were pelleted, washed with CHAPS buffer, and the bound proteins were extracted from the beads in reducing sample buffer. Proteins were resolved on 10\% SDS-polyacrylamide gel, and analyzed by western blotting as described above, using anti-phospho-tyrosine (1:250; BD Biosciences, San Jose, CA, USA) and anti-LRP1 $(1: 1000 ; 11 \mathrm{H} 4)$ antibodies.

\section{Reverse Transcription and Polymerase Chain Reaction}

The primer sequences used (as previously described by $\mathrm{Li}$ et al. ${ }^{17}$ and Vogel et al. ${ }^{18}$ ) were as follows: Collagen I Forward Primer 5'-AAC GGC AAG GTG TTG TGC CAT G-3', Collagen I Reverse Primer 5'-AGC TGG GGA GCA AAG TTT CCT C-3', $\beta$-actin Forward Primer $5^{\prime}$-GAG CTA TGA GCT GCC TGA CG-3', $\beta$-actin Reverse Primer $5^{\prime}$-GTG CTA GGA GCC AGG GCA GTA A-3'. Total RNA was isolated from treated cells using RNABee (Amsbio, Lake Forest, CA, USA)chloroform extraction and precipitated with isopropanol. Isolated total RNA was DNase I-treated using Turbo DNase kit (Life Technologies, Grand Island, NY, USA) according to the manufacturer's instructions. First-strand cDNA was synthesized from DNAse I-treated RNA using SuperScript III reverse transcriptase (Life Technologies) with random hexamers. One hundred nanograms of cDNA from each sample were used for polymerase chain reaction to amplify type I $\alpha 1$-collagen gene (Colla1) or $\beta$-actin gene (Actb). Negative control reactions were run for each primer set in which reverse transcriptase or cDNA template were not added to ensure for specificity of reactions and lack of contamination, respectively (data not shown). PCR consisted of 30 cycles at $94^{\circ} \mathrm{C}$ for $1 \mathrm{~min}, 59^{\circ} \mathrm{C}$ for $1 \mathrm{~min}$, and $72^{\circ} \mathrm{C}$ for $1 \mathrm{~min}$, followed by a final extension step at $72^{\circ} \mathrm{C}$ for $7 \mathrm{~min}$. PCR products were run on a $2 \%$ agarose gel containing ethidium bromide and visualized under UV light for photography.

\section{Carbon Tetrachloride $\left(\mathrm{CCl}_{4}\right)$ Acute Injury and Resolution Experiments}

Male $\mathrm{C} 57 \mathrm{Bl} / 6$ and $\mathrm{t}-\mathrm{PA}^{-1-}$ animals (Jackson Laboratories, Bar Harbor, ME, USA), or LRP $P^{\text {flox/flox }} ;$ SM22-cre ${ }^{+/-}$mice (Strickland laboratory, University of Maryland, Baltimore, MD, USA), aged 10-12 weeks, were given $0.05 \%$ phenobarbital (PB) water ad libitum for 1 week prior to corn oil (control; data not shown) or $\mathrm{CCl}_{4}$ intraperitoneal injections ( $1 \mu \mathrm{l} / \mathrm{g}$ body weight, diluted 1:4 with corn oil for injection; Sigma-Aldrich). Two acute doses of $\mathrm{CCl}_{4}$ were given 3 days apart and mice were collected from 1-14 days after injection ( $n=3-5$ for days $1-7 ; n=2$ for day 14$)$. Others have used these conditions, with $\mathrm{PB}$ specifically utilized as a means of equalizing $\mathrm{CCl}_{4}$ bioactivation. ${ }^{19}$ During the course of the $\mathrm{CCl}_{4}$ experiments, animals were housed in filter-top cages with unlimited water and standard chow placed in outside-vented chemical hoods to limit $\mathrm{CCl}_{4}$ exposure up to day 5 after $\mathrm{CCl}_{4}$ injury. These conditions were in accordance to the recommendations made by the Department of Environmental Health and Safety at the University of Pittsburgh. Total and liver body weights were recorded at the time of killing. Serum and liver tissues were collected for biochemical and histological analyses, with tissues fixed in formalin for paraffin embedding, frozen in OCT for immunofluorescence, and flash frozen in liquid nitrogen for protein and RNA extractions. The University of Pittsburgh Medical CenterPresbyterian Hospital, Department of Pathology Lab Support Services quantified serum alanine transaminase (ALT) levels.

\section{Immunohistochemical Staining and Fluorescent Labeling} Paraffin-embedded livers $(n=3-5$ per time point) were sectioned into $4-\mu \mathrm{m}$ thick slices. Standard immunohistochemistry was performed using anti- $\alpha$-SMA (1:50), antiCollagen I (1:100), and anti-fibrinogen (1:50) primary antibodies with an avidin-biotin complex-horseradish peroxidase developer. Double staining on sections used mouse anti- $\alpha$-SMA (1:50) and rabbit anti-p-LRP1 (1:200) primary antibodies and Qdot-conjugated Q705 and Q605 secondary antibodies, respectively (Life Technologies). Triple staining was accomplished by adding goat anti-t-PA (1:150) labeled with biotinylated secondary and Streptavidin-Q655. Specificity of the $\alpha$-SMA was confirmed using a mouse-on-mouse blocking kit (Vector Laboratories, Burlingame, CA, USA). Sequential double labeling of $4-\mu \mathrm{m}$ thick OCT sections from LRP floxfflox; SM22-cre ${ }^{+/-}$or -/- , and $\mathrm{t}-\mathrm{PA}^{+/+}$or -/- mice $(1: 1$ acetone:MeOH fix) used anti-LRP1 (1:50, American Diagnostica) with a Cy5-conjugated secondary antibody, followed by Cy3-conjugated anti- $\alpha$-SMA (1:1000, Sigma-Aldrich).

\section{Image Capture and Analysis}

The Center for Biologic Imaging at the University of Pittsburgh provided Provis microscopes for brightfield (Olympus, Center Valley, PA, USA), Olympus Fluoview 1000 upright confocal microscopy for fluorescence, and Metamorph software (Sunnyvale, CA, USA) for quantification of positive-staining area and co-localization analyses. For immunohistochemical quantification, low-powered images $(\times 100$ or $\times 200$ total magnification $)$ were taken at regular intervals to cover the majority of the tissue. Edges, large vessel lumens, and artifacts were avoided. Only slides that were stained and imaged simultaneously were compared. Images were thresholded for positive staining and batch analyzed for 
area of staining using the same threshold, expressed as a percentage of the total visual field analyzed. Qdot-labeled tissues were scanned with a Zeiss AxioVision MIRAX MIDI scanner (Carl-Zeiss, Jena, Germany) and single frames were captured with the Panoramic Viewer from 3DHISTECH (Budapest, Hungary).

\section{Statistical Analysis}

Densitometry from scanned western blot and PCR gel images was analyzed using NIH ImageJ 1.42q (National Institutes of Health, USA). For western blots, protein loading and transfer efficiency were normalized using scanned lane images from Ponceau S-stained membranes, prior to immunoblotting, ${ }^{20}$ after verifying this is also a valid control in our hands (Supplementary Figure S1). Statistical analyses were performed using Prism (GraphPad, La Jolla, CA, USA). Numeric values are expressed as the ratio of the treated target/loading control divided by the untreated sample/loading control. Student's $t$-test and paired Student's $t$-test were used to compare two groups and two groups with normalized ratios, respectively. For more than two groups, one-way analysis of variance test was performed with Tukey's post hoc test analyses. Statistical significance was set at $P<0.05$, with variability presented as \pm s.e.m. Statistics were only performed when replicate experiments were run on the same gels due to potential artifacts from differences in exposure times.

\section{Animal Use Approval}

Studies were approved by the University of Pittsburgh Institutional Animal Care and Use Committee in accordance to the 'Guide for the Care and Use of Laboratory Animals' published by the National Institutes of Health. The University of Pittsburgh is an accredited institution by the Association for Assessment and Accreditation of Laboratory Animal Care.

\section{RESULTS}

\section{Exogenous t-PA Decreases Markers of HSC Activation in Primary and Transformed Cells}

To examine the effects of t-PA on HSC phenotype, immortalized HSC cell lines (rat HSC-T6, human LX-2) or primary rat HSCs were treated for $24 \mathrm{~h}$ in serum-free conditions with either t-PA (Figure 1a) or non-proteolytically active t-PA (Figure 1b). All t-PAs tested led to a reproducible decrease in $\alpha$-SMA protein expression, a marker of HSC activation. These data were surprising as previous work in collaboration with our laboratory found that t-PA increased $\alpha$-SMA in the kidney fibroblast cell line NRK-49F. ${ }^{9}$ To rule out possible experimental differences, NRK-49F cells were obtained and treated with t-PA in the same conditions as the HSCs. Supplementary Figure S2 shows that t-PA does indeed induce $\alpha$-SMA in NRK cells, indicating the effects of t-PA are cell type-specific. Next, using HSC-T6 cells or primary cells, we verified that $\mathrm{t}$-PA alters other markers of HSC activation, ie, extracellular matrix production. Figure $1 \mathrm{c}$ shows that Collagen I mRNA expression in primary HSCs decreases after t-PA treatment. Lastly, we looked for changes in cell metabolism and viability in response to t-PA. No changes in MTT and TUNEL were observed with non-proteolytically active t-PA treatment at $48 \mathrm{~h}$ (Figure 1d), although active t-PA did decrease cell viability and increase cell death (Figure 1e). Collectively, these data demonstrate that in vitro, $\mathrm{t}$-PA downregulates markers of HSC activation, and active t-PA can further induce moderate cell death.

\section{The Effects of t-PA on HSC Activation Are Dependent on LRP1-Mediated Signaling}

Although plasmin, only generated by active t-PA, is reportedly anti-fibrotic, ${ }^{21}$ both the proteolytically active and inactive forms of t-PA can signal through the LRP1 receptor. ${ }^{8}$ To determine if the observed decrease in HSC activation is mediated through LRP1, HSC-T6 cells were treated with t-PA and protein isolates were analyzed for phosphorylation of LRP1. Following immunoprecipitation with anti-LRP1, an $85-\mathrm{kDa}$ phosphorylated band that migrates at the same molecular weight as the $\beta$-chain of LRP1 was selectively increased after treatment (Figure 2a). As a second, nonspecific phosphorylated band within the same size range was also detected by the immune control in the t-PA-treated samples, to verify the individual band was truly phosphoLRP1, we further probed whole-cell lysates with a phosphospecific antibody against the Tyr4507 residue of LRP1. These results confirm that increased LRP1 phosphorylation was detected within $1 \mathrm{~min}$ of t-PA addition in HSC-T6 and primary rat HSCs (Figure 2b).

Phosphorylation of tyrosine 4507 within the LRP1 cytoplasmic domain is essential for LRP1-dependent downstream signaling. ${ }^{22,23}$ To test whether t-PA acts through known signaling targets of LRP1, the Akt and ERK pathways were examined. Both Akt and ERK were activated in t-PA treated HSC-T6 cells within 10 min post-treatment (Supplementary Figures S3A and B). Inhibition of the ERK pathway was ineffective in changing outcome (data not shown); however, the effects of t-PA on HSC activation were abolished in the presence of the PI3K/Akt pathway inhibitor LY294002 (Figures 2c and d). Interestingly, an increase in total Akt was consistently observed when only LY294002 was present but notably, the two t-PA minus controls displayed correlative values for their $\mathrm{p}$-Akt/Akt ratios.

To further confirm the effects we observed were dependent upon signaling through LRP1, cells were treated with the receptor-associated protein (RAP), a specific inhibitor of ligand binding to LRP1. ${ }^{24}$ RAP pretreatment abrogated both Akt phosphorylation (Figure 2e) and the subsequent suppression of $\alpha$-SMA (Figure 2f) although unexpectedly, t-PA significantly increased $\alpha$-SMA expression when RAP was present. We conclude LRP1 signaling through Akt is necessary for the t-PA-mediated suppression of $\alpha$-SMA expression. 
a

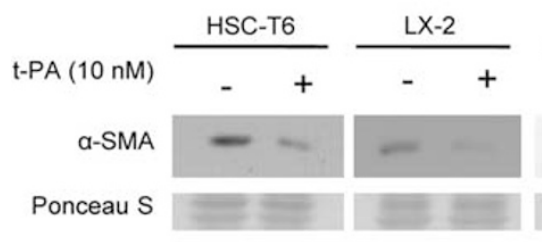

b

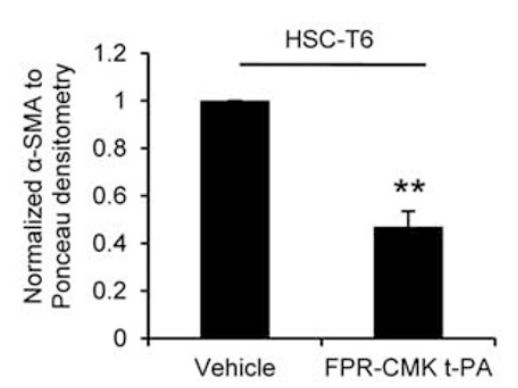

d

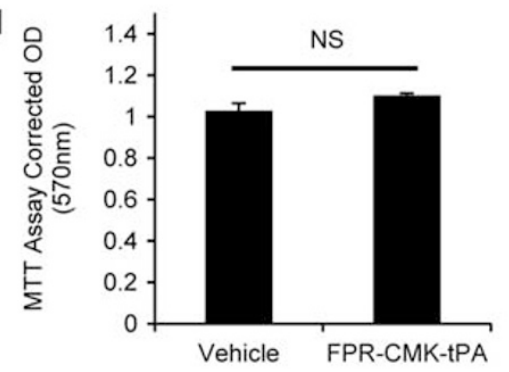

e

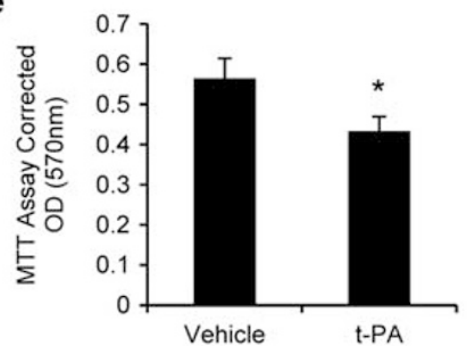

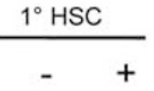

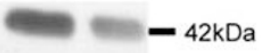

- 42kDa

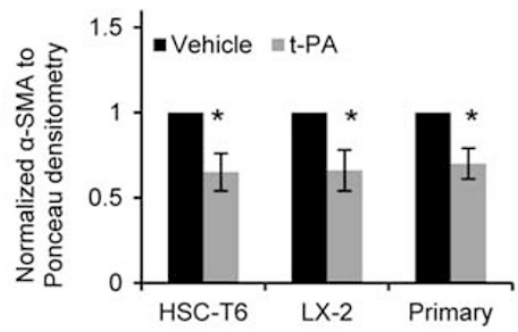

C
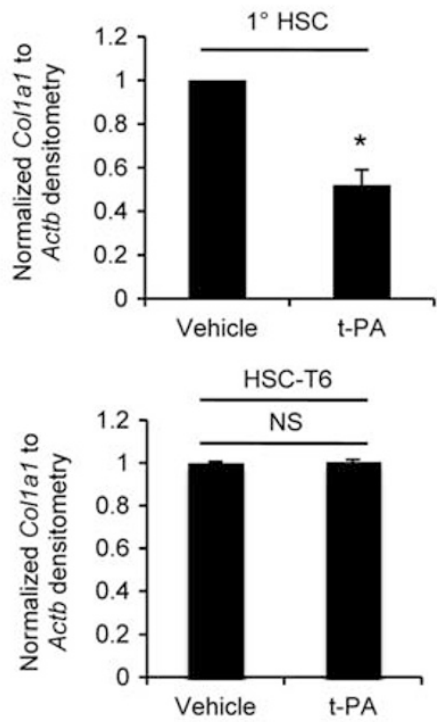

Figure 1 t-PA inhibits HSC activation in cultured cells. (a) Representative $a$-SMA western blots on HSC-T6, LX-2, or primary rat HSCs treated with exogenous t-PA for $24 \mathrm{~h}$, using pooled whole-cell lysates ( $n=2-3 /$ well); quantification on right ( $n=5$ independent experiments per cell source). (b) Quantifications of western blots for $a$-SMA on lysates from HSC-T6 cells treated for $24 \mathrm{~h}$ with protease-inactivated t-PA $(n=4)$ ). (c) RT-PCR for Col1a 1 mRNA expression in primary HSCs or HSC-T6 cells after $24 \mathrm{~h}$ t-PA treatment; quantification on right ( $n=3$ and 4, respectively). (d and e) HSC-T6 cells stimulated with protease-inactivated t-PA (d) or t-PA (e) for $48 \mathrm{~h}$ before measuring mitochondrial function (MTT reduction assay; $n=3$ ) or apoptosis (TUNEL labeling). Error bars \pm s.e.m. ${ }^{*} P<0.05,{ }^{*} P<0.01,{ }^{* * *} P<0.001$, Student's paired (a and $\mathbf{b}$ ) or unpaired (c-e) $t$-test. 


\section{p-LRP1 and t-PA Co-Localization with $a$-SMA Precedes Resolution of Injury in WT Mice}

As the in vitro data indicated that LRP1-mediated signaling decreases HSC activation markers, we hypothesized that t-PA would regulate HSC activation in vivo as well. To begin to test this hypothesis, we first determined the timing of HSC regressions during resolution of an acute, in vivo injury. WT

a

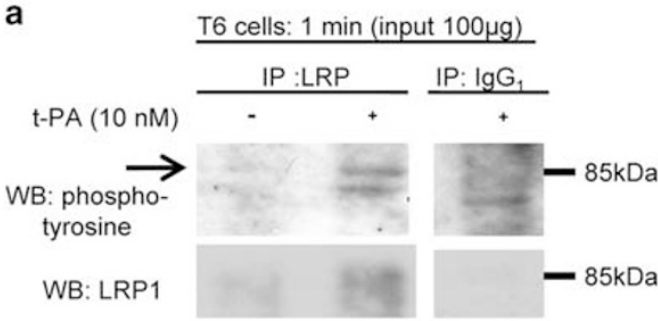

c

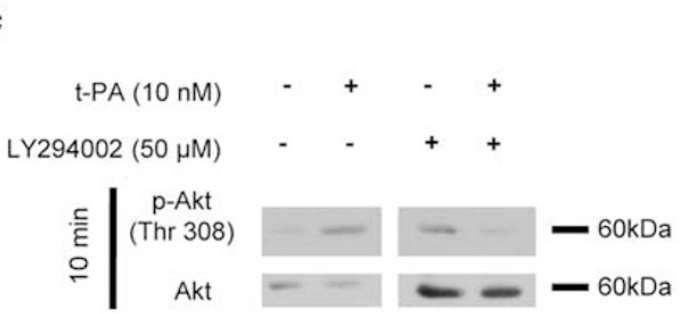

e

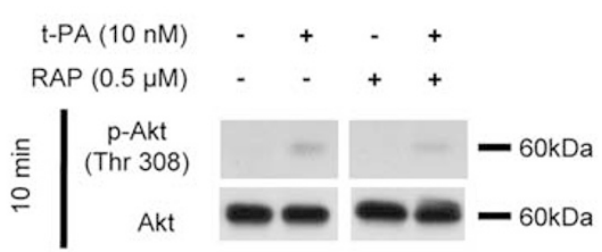

mice were subject to acute liver injury by $\mathrm{CCl}_{4}$ and allowed to recover for up to 14 days. Tissue sections were stained for $\alpha$ SMA which is absent in quiescent mouse HSCs. ${ }^{1}$ As shown in Figure 3a, the $\alpha$-SMA ${ }^{+}$population drops off significantly between days 4 and 5 after acute liver injury, and if our hypothesis is correct, we anticipate that p-LRP1, primarily absent in resting liver, should be detected on activated stellate

b
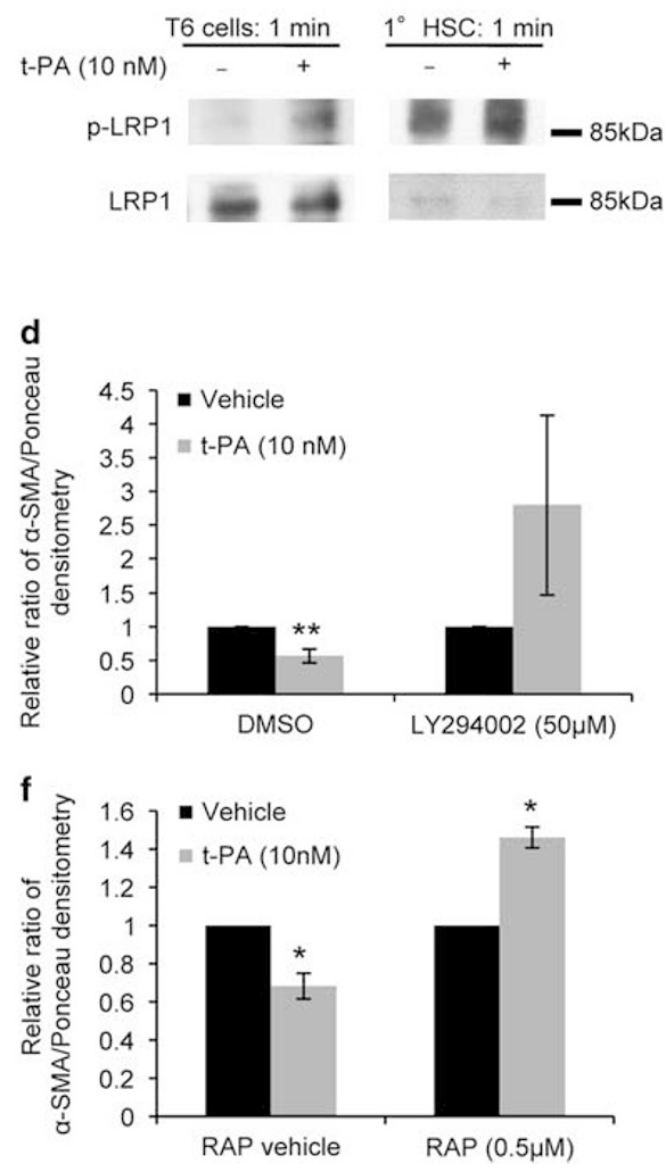

Figure 2 The effects of t-PA on HSC activation are mediated by LRP1-dependent signaling. Whole-cell lysates either immunoprecipitated with anti-LRP1 followed by western blot for phospho-tyrosine and LRP1 in parallel (a), or directly analyzed by western blot with antibodies against p-LRP1 and total LRP1 (b). (c and d) HSC-T6 cells pretreated with PI3K pathway inhibitor LY294002 or DMSO for 60 min before co-treatment with t-PA or vehicle for $10 \mathrm{~min}(\mathbf{c})$ or $24 \mathrm{~h} \mathrm{(d).} \mathrm{(e} \mathrm{and} \mathrm{f)} \mathrm{HSC-T6} \mathrm{cells} \mathrm{acid-washed} \mathrm{(pH} \mathrm{5)} \mathrm{at} 4{ }^{\circ} \mathrm{C}$ to dissociate endogenous ligands, pretreated with the LRP1 inhibitor RAP or vehicle for $30 \mathrm{~min}$, then co-treated with t-PA or vehicle for $10 \mathrm{~min}$ (e) or $24 \mathrm{~h}(\mathbf{f})$. ( $n=6$ and 3 for $\mathbf{d}$ and $\mathbf{f}$, respectively.) Panels compared in a, c, and e are noncontiguous lanes from single blots. Error bars \pm s.e.m. ${ }^{*} P<0.05$ and ${ }^{* *} P<0.01$, Student's paired $t$-test.

Figure 3 LRP1 is tyrosine phosphorylated in HSCs during resolution of acute hepatic injury in vivo. (a) Quantification of $a$-SMA immunohistochemistry on tissue sections from WT mice after acute $\mathrm{CCl}_{4}$ injury as described in MATERIALS AND METHODS $(\times 10$ images, minimum 10$)$. ${ }^{*} P<0.05$, one-way ANOVA with post-test comparisons; only sequential differences denoted. Error bars \pm s.e.m. (b) Standard immunohistochemistry (upper panels, $a$-SMA) or double Qdot-labeled immunohistochemistry for p-LRP1 and $a$-SMA (middle and lower panels), with percent $a$-SMA/p-LRP co-localization area of total $a$ SMA staining indicated below each time point. Arrows indicate co-localization. Bottom panels are higher magnifications of boxed regions in the middle panels. Days indicated are post-CCL 4 . (c) Qdot-labeled immunohistochemistry for $a$-SMA, t-PA, and p-LRP1 on day 4 post-CCL4. Selected channels separated from the same image shown for comparison. Arrow indicates triple co-location, arrowhead indicates $a$-SMA/t-PA co-localization. Scale bars, $20 \mu \mathrm{m}$. 
a

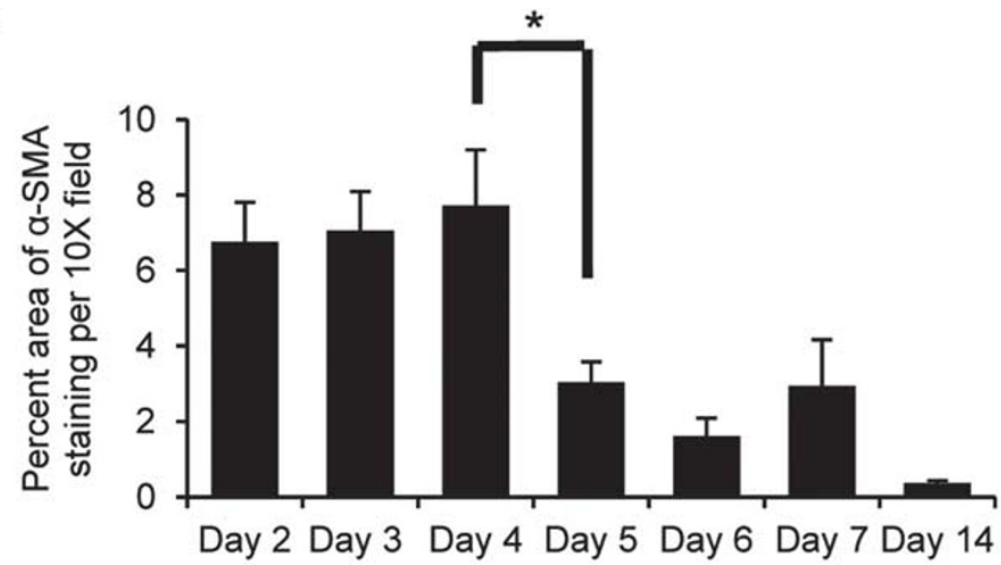

Number of days recovery after acute injury

b
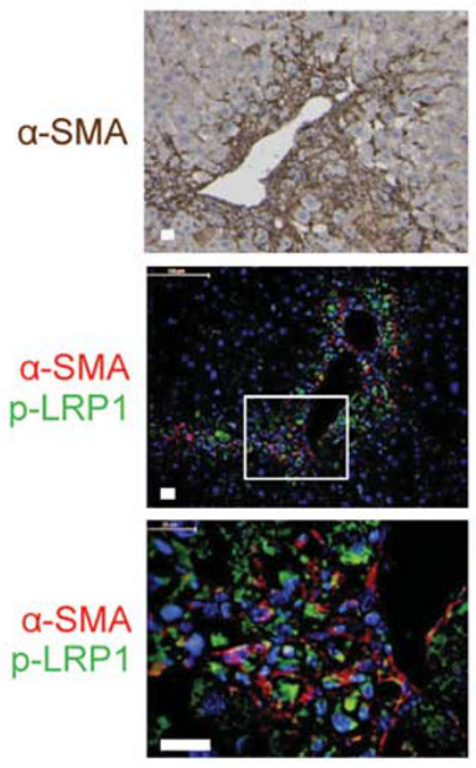

$\%$ a-SMA

co-localized

with $\mathrm{p}-\mathrm{LRP} 1$

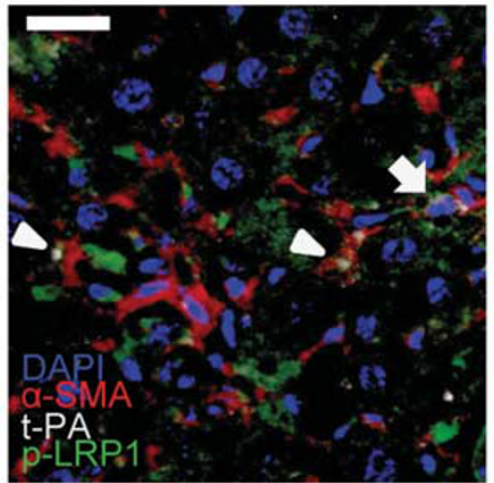

Day 4
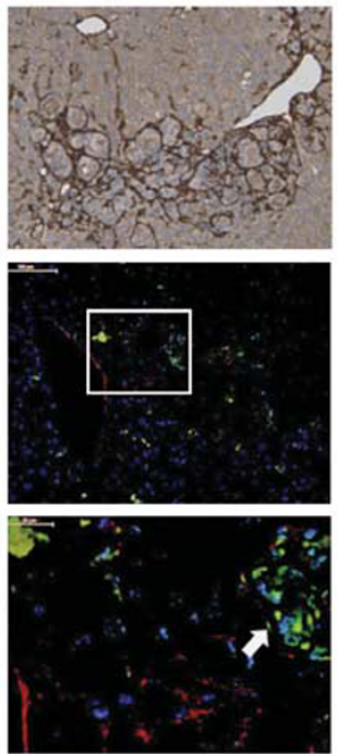

36.7
Day 5
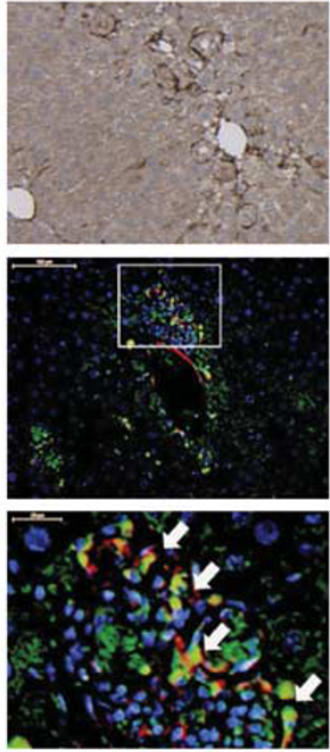

51.0
Day 14
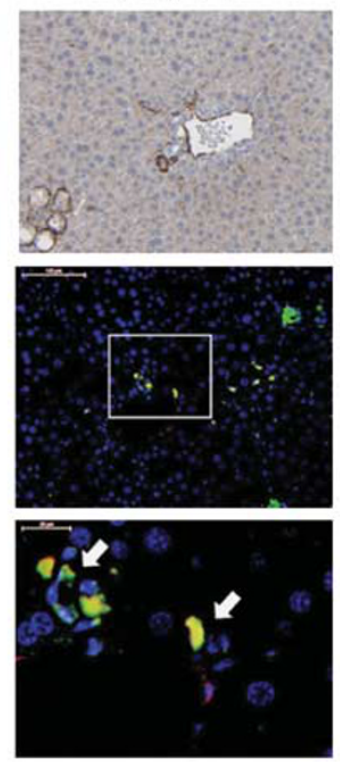

69.9

\section{C}
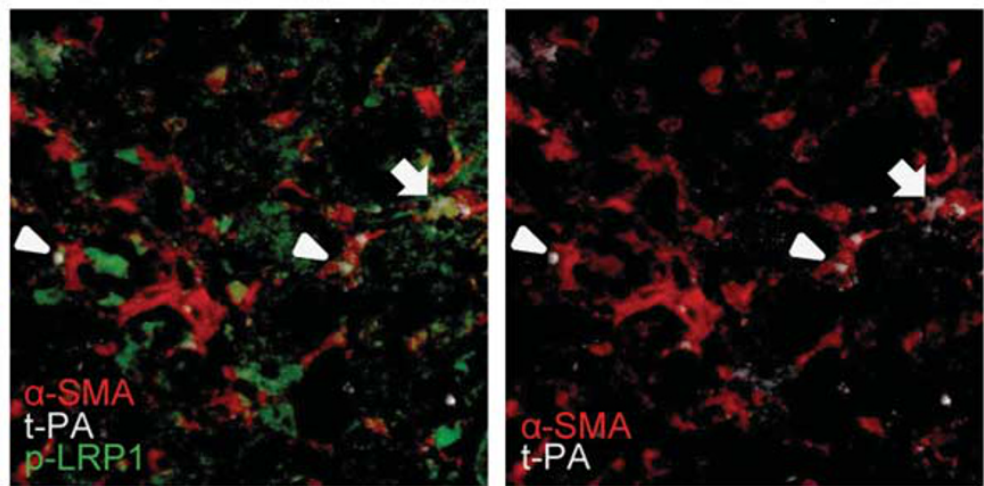
cells at this time. Next, co-immunolocalization of p-LRP1 and $\alpha$-SMA was performed, spanning the same time points (Figure 3b). As phosphorylation of LRP is transient and the half-life of $\alpha$-SMA is $72 \mathrm{~h},{ }^{25}$ we expected to only identify a fraction of $\alpha$-SMA-positive cells that were also p-LRP1 positive. Strikingly, at day 3 , very little co-localization was observed $(16.6 \%)$, suggesting the presence of p-LRP only in other hepatic cell types (Figure 3b). At day 4, increased colocalization was apparent (36.7\%); however, from day 5 onward, co-localization was readily observed visually and by software analysis, correlating with the time frame of loss of $\alpha$ SMA-positive cells as observed in Figure 3a. The magnified inserts shown in Figure 3b highlight non-vascular $\alpha$-SMA+ regions in order to focus on de novo activated HSCs, rather than $\alpha$-SMA+ vascular smooth muscle cells.

As LRP1 is present on several cell types and can be activated by a variety of ligands, sections from WT mice were coimmunolabeled at day 4 of recovery with antibodies against t-PA, p-LRP1, and $\alpha$-SMA. Although sparse, regions were identified where all three proteins were co-localized in addition to several regions with t-PA adjacent to $\alpha$-SMA ${ }^{+}$ cells (arrow and arrowheads, respectively, Figure 3c). This indicates in situ proximity of t-PA with activated HSCs just prior to the observed increased in HSC p-LRP1 (day 5; Figure $3 \mathrm{~b}$ ), further implicating t-PA-LRP1 interactions in the resolution of HSC activation during liver repair.

\section{t-PA- and LRP1-Deficient Mice Retain More $a$-SMA- Positive Cells After Injury}

We next examined t-PA null mice ${ }^{26}$ and assessed whether regression of activated HSCs was impaired compared with WT. Although mice lacking t-PA are known to have impaired fibrin clearance and liver repair through day 7 after injury, ${ }^{4}$ HSC activation was previously not examined. Similar to Bezerra et al, ${ }^{4}$ no significant differences were detected in the extent of parenchymal injury between WT and t-PA null mice post-injury (Figure 4a); however, t-PA null mice had significantly larger areas of $\alpha$-SMA-positive-staining per visual field, beginning at day 5 when injury starts resolving in WT (Figure $4 \mathrm{~b}$ ). Hence, overall loss of t-PA affects recovery through maintenance of an $\alpha$-SMA-positive cell population.

As t-PA is globally inactivated in the null mice, we next specifically tested the involvement of LRP1 on activated HSCs by repeating the experiment using conditional LRP1 knockout mice. ${ }^{27} \mathrm{SM} 22$, or transgelin, is a smooth muscle cell marker selectively expressed in quiescent and activated HSCs. ${ }^{28}$ Hence, LRP ${ }^{\text {flox/flox }}$; SM22-Cre ${ }^{+}$animals harbor HSCs with a selective deletion for LRP1. Age-matched LRP ${ }^{\text {flox/flox; }}$; SM22-Cre ${ }^{+}$mice and genetically matched controls $\left(\mathrm{Cre}^{-}\right)$ were subjected to $\mathrm{CCl}_{4}$-treatment and killed at days 4 and 6 post-injury. The loss of HSC LRP1 was confirmed by performing double immunolabeling with LRP1 and $\alpha$-SMA. Although LRP1 remained on other hepatic cell types, a decrease in co-localized signal, relative to total $\alpha$-SMA, was observed at day 4 in the $\mathrm{LRP}^{\text {flox/flox}}$; SM22-Cre ${ }^{+}$(LRP1 cKO) mice (Figure 5a). Similar to t-PA null mice, despite no change in parenchymal injury by either day 4 or 6 after injury (Figure 5b), conditional KO mice retained more $\alpha-\mathrm{SMA}^{+}$cells than control mice during recovery (Figure $5 \mathrm{c}$ ). In addition, more Type I collagen was deposited in the tissue of LRP1 conditional KOs at day 4 after injury (Figure 5d). Liver to body weight ratios were not statistically different. Staining for fibrin in the both t-PA and LRP null animals was not different $v s$ their wild-type counterparts (see Supplementary Figure S4), similar to the findings of Bezerra et al. ${ }^{4}$

\section{DISCUSSION}

HSCs are crucial for development of liver fibrogenesis; their depletion leads to marked amelioration of fibrogenesis and, downregulation of MFB-like cell markers following chronic liver injury. ${ }^{29}$ Hence, developing anti-fibrotic therapies to treat hepatic fibrosis/cirrhosis can potentially decrease morbidity and mortality in patients with chronic liver diseases ${ }^{30}$ who are at risk for hepatocellular carcinoma. ${ }^{31}$ This study identifies the t-PA/LRP1 ligand/receptor pair on activated HSCs as potential new targets for anti-fibrotic therapies.

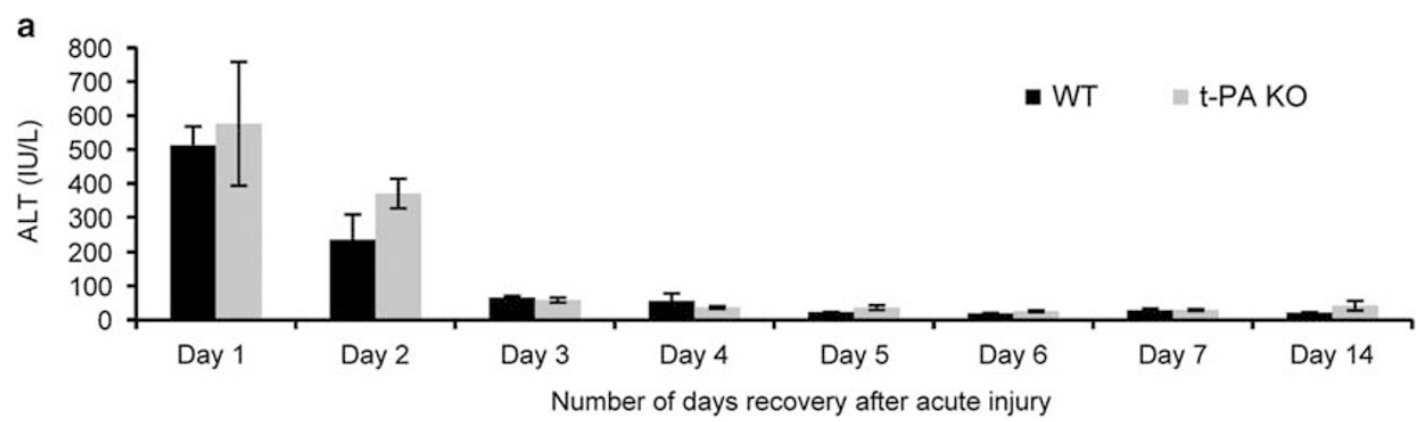

Figure 4 t-PA promotes efficient resolution of acute hepatic injury in mice. C57BI/6 (WT) and t-PA null mice (t-PA KO) analyzed at days 1-7 and 14 post- $\mathrm{CCL}_{4}$ injury as described in MATERIALS AND METHODS. (a) Serum ALT values in WT and t-PA KO mice. No values were significantly different at time points indicated. (b) Quantification of $\alpha$-SMA staining ( $\times 20$ images, minimum 10/animal). Sections from WT and KO mice on matching days were stained, imaged, and analyzed together. Representative images are shown. Error bars \pm s.e.m. ${ }^{*} P<0.05,{ }^{* *} P<0.01,{ }^{* * *} P<0.001$, unpaired Student's $t$-test. Scale bars, $50 \mu \mathrm{m}$. 
b
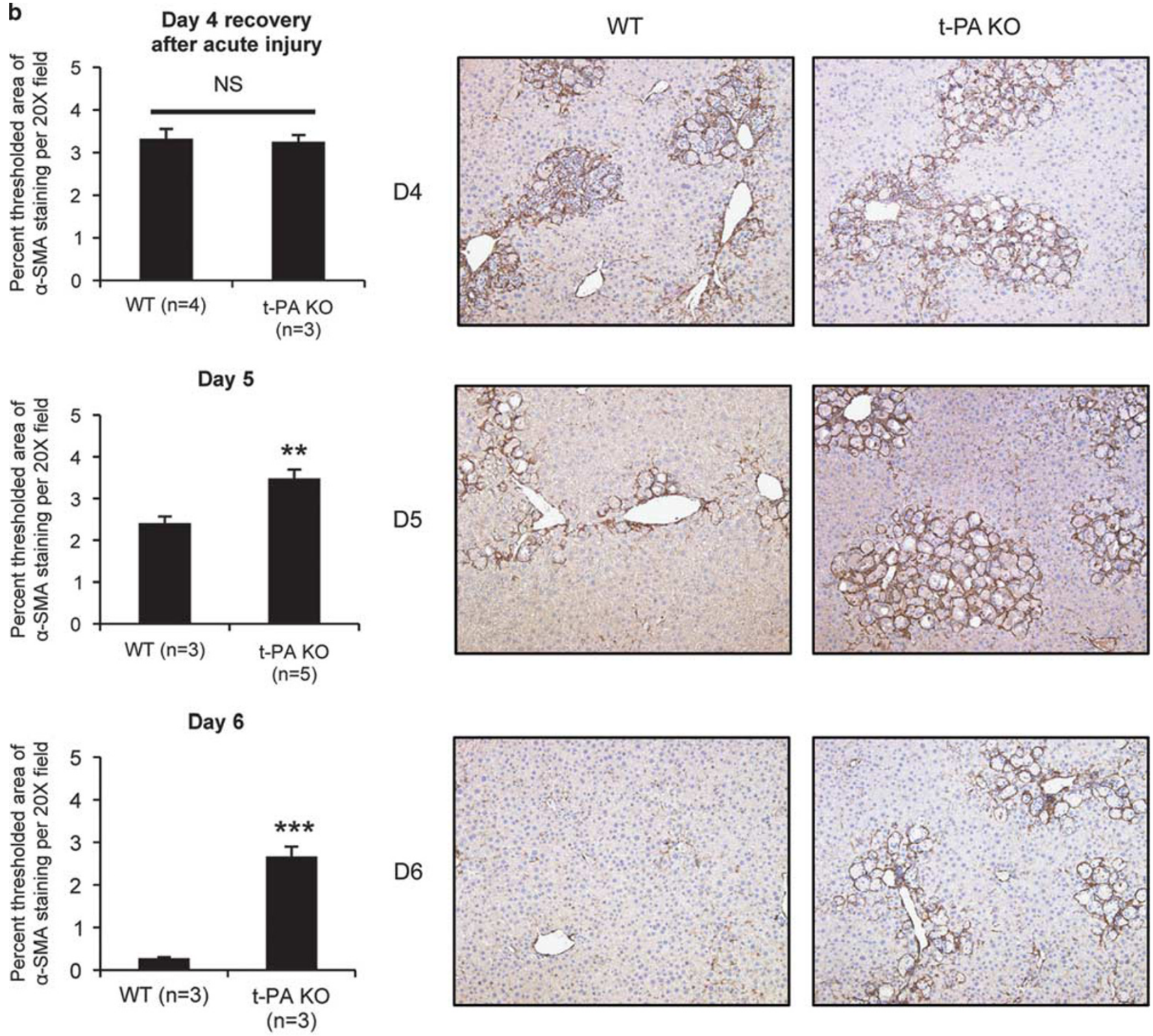

Day 7
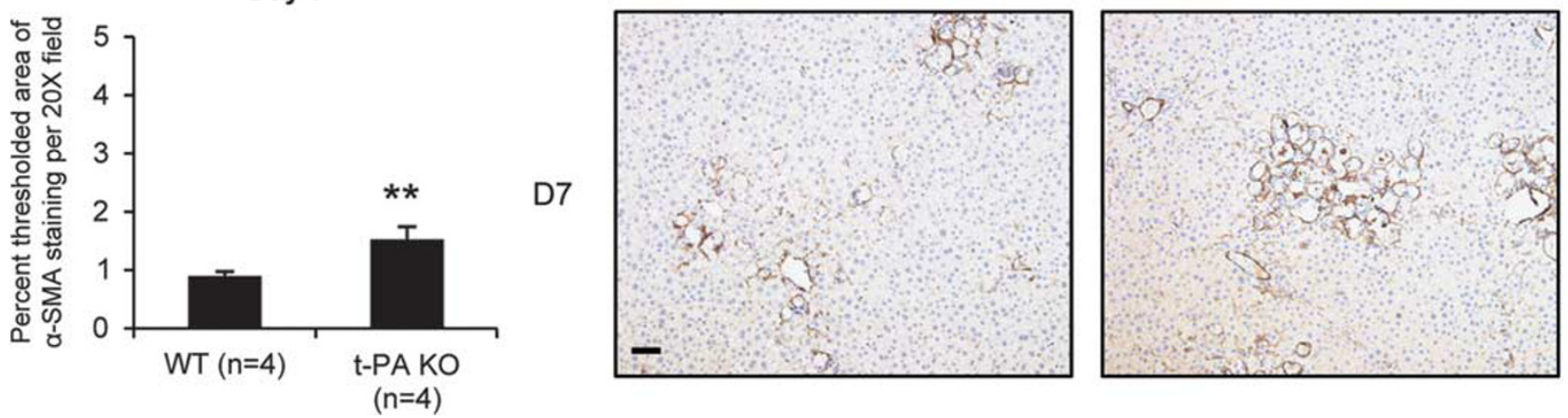

Figure 4 Continued. 


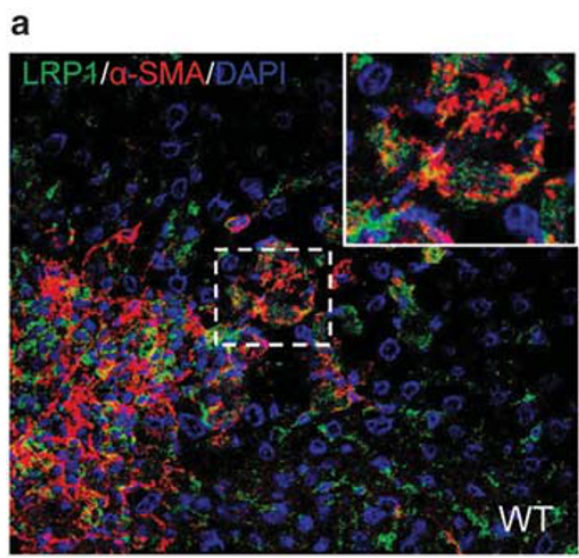

b

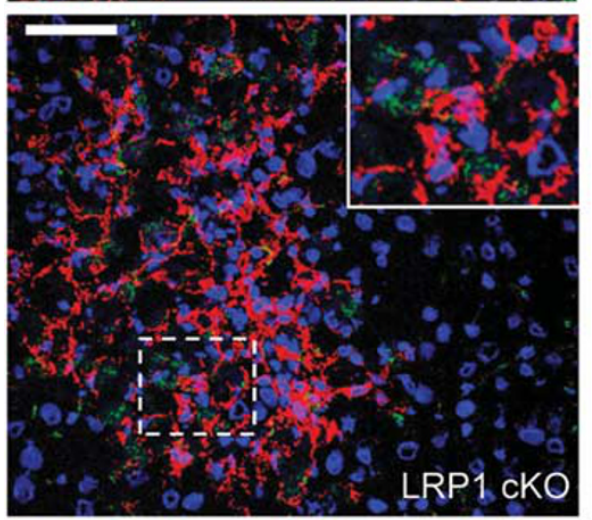

Day 4 recovery after acute injury

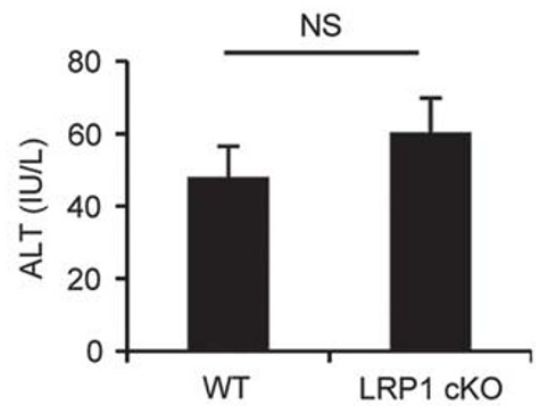

Day 6 recovery after acute injury

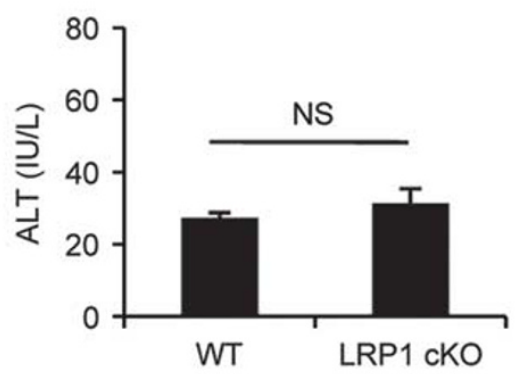

c

Day 4 recovery after acute injury

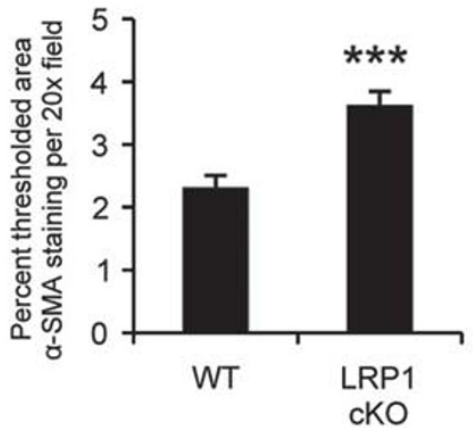

D4

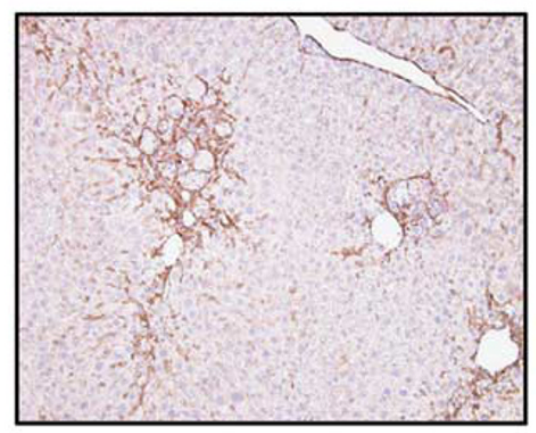

a-SMA

Day 6 recovery after acute injury
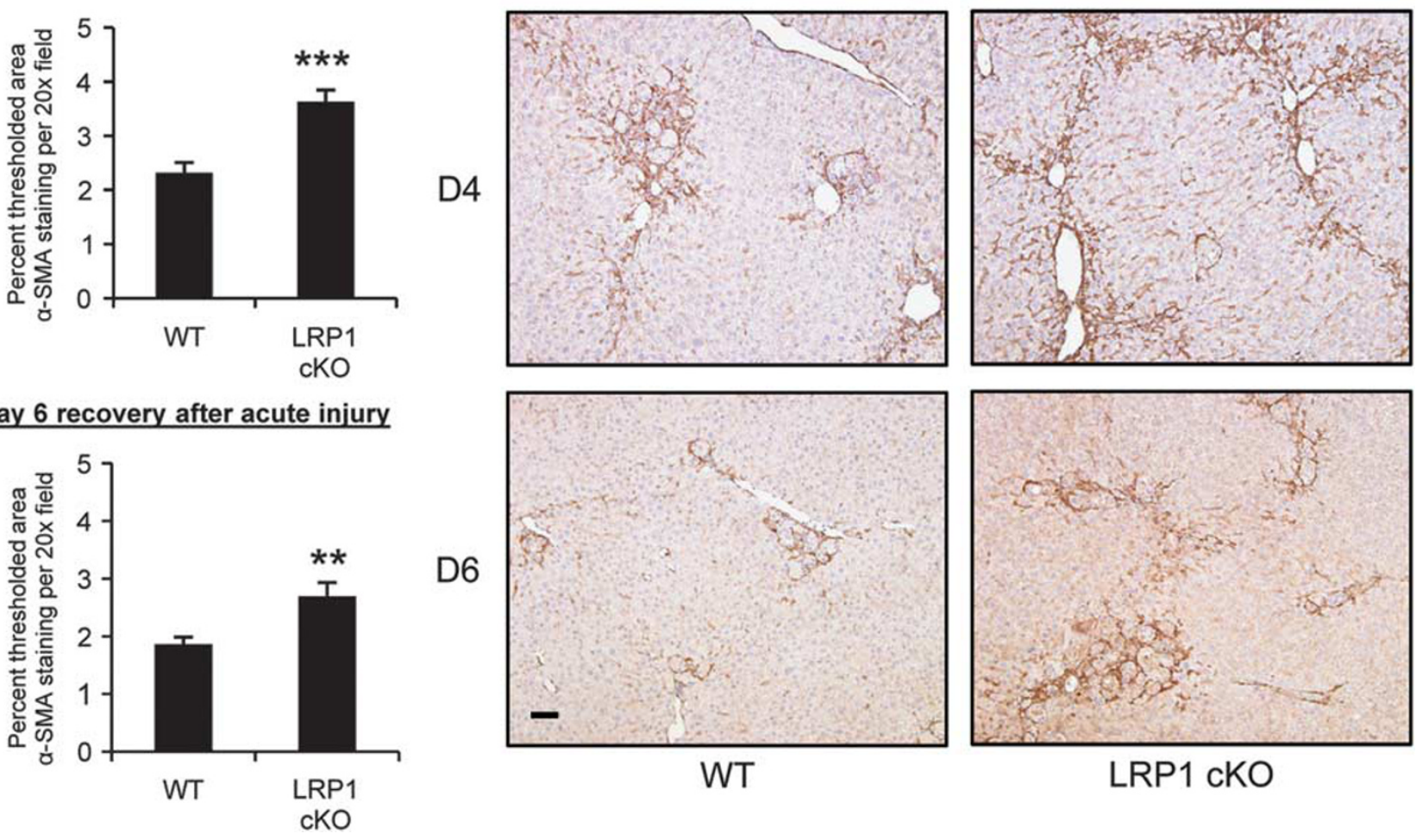
LRP1 is a multi-functional receptor with a plethora of ligands. ${ }^{8}$ In liver, LRP1 is generally known as a hepatocellular clearance receptor for t-PA. ${ }^{32}$ Although several studies have indicated a role for t-PA during acute injury repair, ${ }^{4,5}$ little is known with regard to the mechanisms involved, including affected cell types. A recent in vitro study demonstrated that LRP1 can mediate anti-proliferative and anti-migratory functions in HSCs. ${ }^{11}$ Our data expands upon that study by (i) identifying t-PA as a signaling ligand for HSC LRP1, (ii) expanding the in vitro changes to phenotypic transformation, and (iii) confirming that these effects are relevant in vivo.

$\mathrm{t}-\mathrm{PA}$ is an FDA-approved drug, making it an attractive candidate for anti-fibrotic therapy; however, our findings open up several interesting questions that must first be addressed. First, although proteolytically active and inactive
t-PA were both able to signal through LRP1 in vitro, only active t-PA was pro-apoptotic (Figures $1 \mathrm{~d}$ and e). This suggests that in vivo, t-PA regulates both populations of activated HSCs described by Kisseleva et al, ${ }^{33}$ ie, the cells that die and the cells that revert but remain and are easily reactivated. Targeting cell death with active t-PA may prove challenging, yet inactive t-PA may not prove sufficient. Second, although t-PA-mediated signaling through LRP1 on HSCs decreases their activation, the exact opposite outcome is observed in a model of kidney fibrosis where complex formation between LRP1 and $\beta 1$ integrin $^{9}$ is pro-fibrotic via the ERK pathway. ${ }^{34}$ Notably, we also observed transient ERK activation (Supplementary Figure 3B), although we were unable to block the effects of t-PA through pathway-specific inhibitors (data not shown). Furthermore, t-PA also acted as a

\section{d}

\section{Day 4 recovery after acute injury}
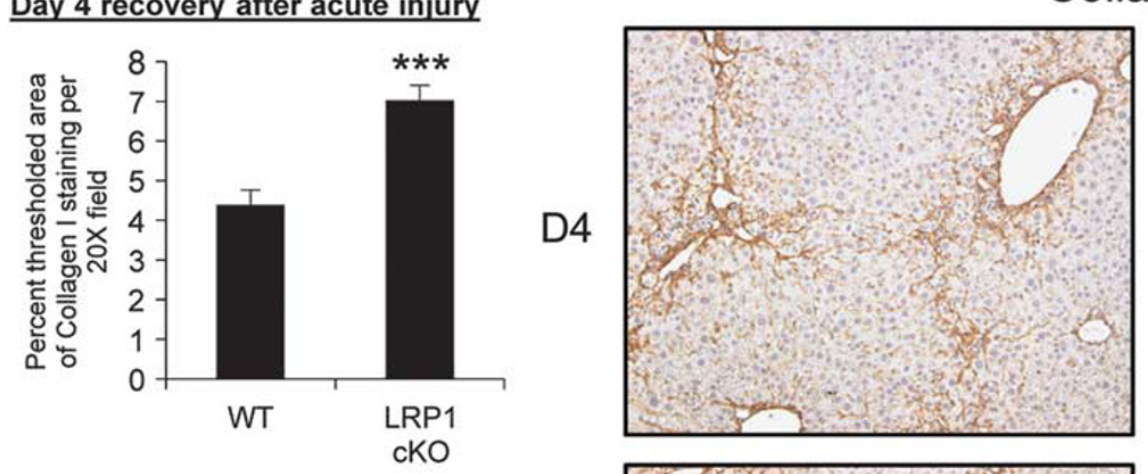

\section{Collagen I}

\section{Day 6 recovery after acute injury}
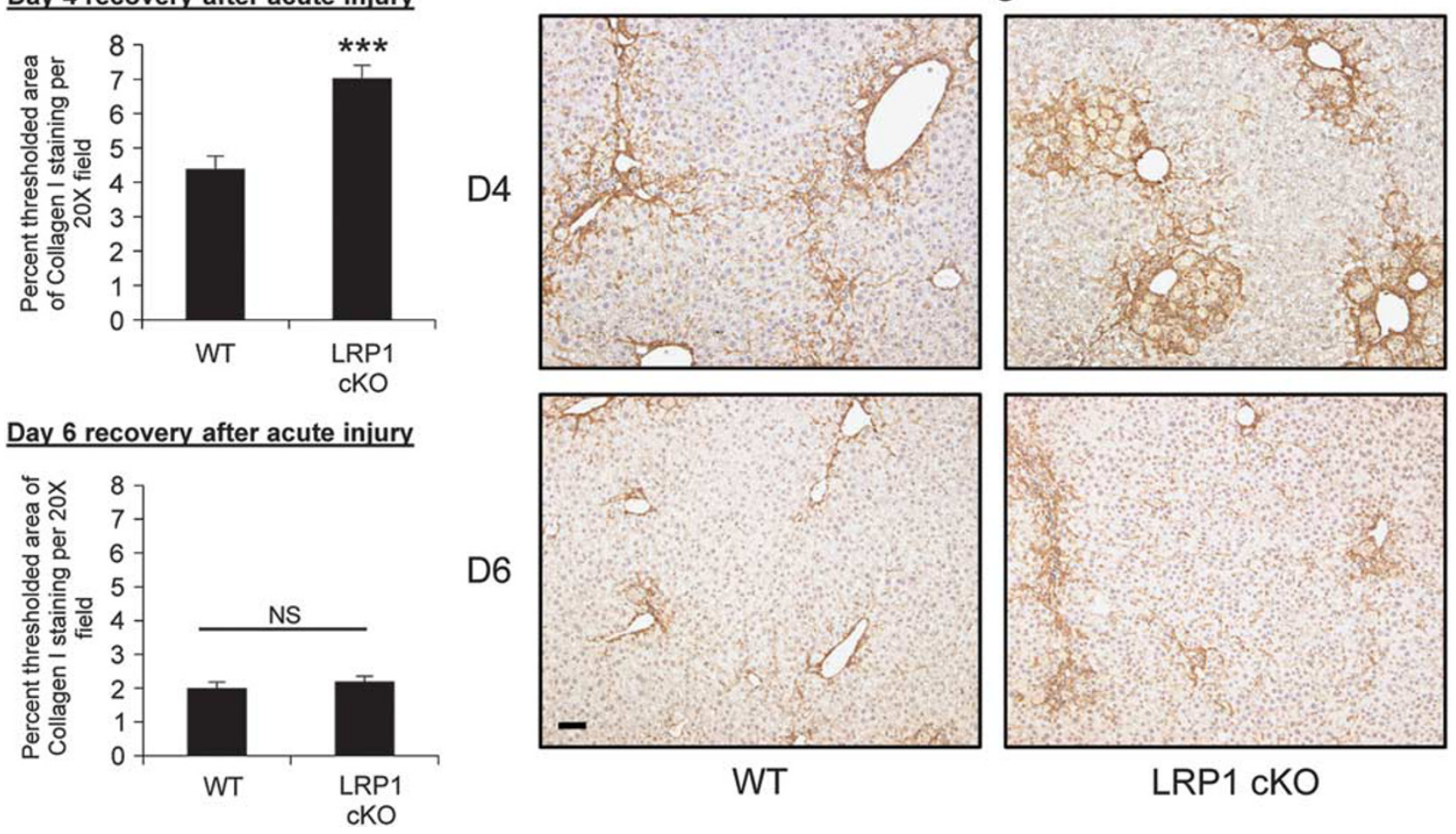

Figure 5 Continued.

Figure 5 Genetic deletion of LRP1 in HSCs reveals its contribution to resolution of hepatic injury and matrix deposition. $L R P^{\text {flox/flox }}$ (WT) and $L R P^{\text {flox/flox; }}$ SM22-Cre ${ }^{+}$(LRP1 CKO) mice treated with $\mathrm{CCL}_{4}$ as described in MATERIALS AND METHODS. Liver tissue and serum were collected at days 4 and 6 after the last dose. ( $n=3$ animals for each time point and genotype). (a) Representative confocal images of double immunolabeling with anti-LRP1 and antia-SMA antibodies of sections from day 4 post-injury. Area inside the dotted squares is shown in the insert. Yellow staining indicates co-localization of LRP1 and $a$-SMA. Scale bars, $50 \mu \mathrm{m}$. (b) Serum ALT values in WT and LRP1 cKO mice at 4 and 6 days after the last CCL 4 injection. (c and d) Representative images (left) and quantification (right) for immunohistochemistry for $a$-SMA (c) and Collagen I (d) at the indicated time points after injury. Sections from WT and $c K O$ mice on matching days were stained, imaged, and analyzed together. Error bars \pm s.e.m. ${ }^{*} P<0.05$, ${ }^{* *} P<0.01$, *** $P<0.001$, unpaired Student's $t$-test. Scale bars, $50 \mu \mathrm{m}$. 
pro-fibrotic in our system, but only when binding to LRP1 was prohibited (Figure 2f). Combined, these findings suggest that either there are other LRP1 co-receptors, ${ }^{9,35,36}$ other LRP1 ligands, and/or other t-PA receptors ${ }^{37}$ that regulate the outcome. Refined mechanistic studies are still needed to fully parse out the anti- $v s$ pro-fibrotic pathways mediated by t-PA and the role of LRP1-mediated signaling in these processes. Finally, the function of t-PA in chronic liver injury remains unclear; two independent studies utilized t-PA null mice in prolonged $\mathrm{CCl}_{4}$ fibrosis protocols and reported opposite results. ${ }^{6,7}$ Interestingly, the longer study (6vs 4 weeks of $\mathrm{CCl}_{4}$ treatment) reported less fibrosis in the t-PA null animals as compared with their WT counterparts, despite an increase in liver damage and necrosis. This suggests that extended insults to the liver are invoking important changes in the microenvironment that both alter outcome and are related to t-PA. Importantly, neither chronic study examined the contribution of LRP1 to this process, nor did they examine the ability of t-PA null animals to resolve fibrosis. Hence, a logical next step is to examine the roles of t-PA and LRP1 during resolution of chronic hepatic injury to better determine if $\mathrm{t}-\mathrm{PA}$ has potential to become a realistic tool for treating patients.

Supplementary Information accompanies the paper on the Laboratory Investigation website (http://www.laboratoryinvestigation.org)

\section{ACKNOWLEDGMENTS}

We acknowledge the Friedman Laboratory for use of the LX-2 and HSC-T6 cell lines, and Anne Orr, Michael Q Ding, and Meagan Haynes for technical support. We also thank Dr Anthony J Demetris for the use of his laboratory's Qdot facilities and expertise. This work has been supported by NIH grants CA30241 and CA35373 (GKM), HL072929 (DKS), HL120388 (DKS), HL114379 (DKS), UL1 RR024153 and UL1 TR000005 (University of Pittsburgh CTSI; LIK), F30 DK091959 (LIK), T32-HL094295 (WMM), and T32-HL007698 (SMC).

\section{DISCLOSURE/CONFLICT OF INTEREST}

The authors declare no conflict of interest.

1. Friedman SL. Hepatic stellate cells: protean, multifunctional, and enigmatic cells of the liver. Physiol Rev 2008;88:125-172.

2. Cao C, Lawrence DA, Li Y et al. Endocytic receptor LRP together with tPA and PAl-1 coordinates Mac-1-dependent macrophage migration. EMBO J 2006;25:1860-1870.

3. Mars WM, Zarnegar R, Michalopoulos GK. Activation of hepatocyte growth factor by the plasminogen activators UPA and tPA. Am J Pathol 1993;143:949-958.

4. Bezerra JA, Currier AR, Melin-Aldana $\mathrm{H}$ et al. Plasminogen activators direct reorganization of the liver lobule after acute injury. Am J Pathol 2001;158:921-929.

5. Wang $\mathrm{H}$, Zhang $\mathrm{Y}$, Heuckeroth RO. Tissue-type plasminogen activator deficiency exacerbates cholestatic liver injury in mice. Hepatology 2007;45:1527-1537.

6. Higazi AA, El-Haj M, Melhem A et al. Immunomodulatory effects of plasminogen activators on hepatic fibrogenesis. Clin Exp Immunol 2008;152:163-173.

7. Hsiao Y, Zou T, Ling CC et al. Disruption of tissue-type plasminogen activator gene in mice aggravated liver fibrosis. J Gastroenterol Hepatol 2008;23:e258-e264.

8. Lillis AP, Van Duyn LB, Murphy-Ullrich JE et al. LDL receptor-related protein 1: unique tissue-specific functions revealed by selective gene knockout studies. Physiol Rev 2008;88:887-918.
9. $\mathrm{Hu} \mathrm{K}, \mathrm{Wu} \mathrm{C}$, Mars WM et al. Tissue-type plasminogen activator promotes murine myofibroblast activation through LDL receptorrelated protein 1-mediated integrin signaling. J Clin Invest 2007;117: 3821-3832.

10. Gao R, Brigstock DR. Low density lipoprotein receptor-related protein (LRP) is a heparin-dependent adhesion receptor for connective tissue growth factor (CTGF) in rat activated hepatic stellate cells. Hepatol Res 2003;27:214-220.

11. Llorente-Cortes V, Barbarigo V, Badimon L. Low density lipoprotein receptor-related protein 1 modulates the proliferation and migration of human hepatic stellate cells. J Cell Physiol 2012;227: 3528-3533.

12. Migliorini MM, Behre EH, Brew S et al. Allosteric modulation of ligand binding to low density lipoprotein receptor-related protein by the receptor-associated protein requires critical lysine residues within its carboxyl-terminal domain. J Biol Chem 2003;278:17986-17992.

13. Riccalton-Banks $L$, Bhandari $R$, Fry J et al. A simple method for the simultaneous isolation of stellate cells and hepatocytes from rat liver tissue. Mol Cell Biochem 2003;248:97-102.

14. Seglen PO. Preparation of isolated rat liver cells. Methods Cell Biol 1976;13:29-83.

15. Kost DP, Michalopoulos GK. Effect of $2 \%$ dimethyl sulfoxide on the mitogenic properties of epidermal growth factor and hepatocyte growth factor in primary hepatocyte culture. J Cell Physiol 1991;147: 274-280.

16. Lagoa $C E$, Vodovotz $Y$, Stolz $D B$ et al. The role of hepatic type 1 plasminogen activator inhibitor (PAl-1) during murine hemorrhagic shock. Hepatology 2005;42:390-399.

17. Li Y, Spataro BC, Yang J et al. 1,25-dihydroxyvitamin D inhibits renal interstitial myofibroblast activation by inducing hepatocyte growth factor expression. Kidney Int 2005;68:1500-1510.

18. Vogel S, Piantedosi R, Frank J et al. An immortalized rat liver stellate cell line (HSC-T6): a new cell model for the study of retinoid metabolism in vitro. J Lipid Res 2000;41:882-893.

19. Kovalovich K, DeAngelis RA, Li W et al. Increased toxin-induced liver injury and fibrosis in interleukin-6-deficient mice. Hepatology 2000;31: 149-159.

20. Romero-Calvo I, Ocon B, Martinez-Moya P et al. Reversible Ponceau staining as a loading control alternative to actin in Western blots. Anal Biochem 2010;401:318-320.

21. Martinez-Rizo A, Bueno-Topete $M$, Gonzalez-Cuevas J et al. Plasmin plays a key role in the regulation of profibrogenic molecules in hepatic stellate cells. Liver Int 2010;30:298-310.

22. Betts GN, van der Geer P, Komives EA. Structural and functional consequences of tyrosine phosphorylation in the LRP1 cytoplasmic domain. J Biol Chem 2008;283:15656-15664.

23. Martin AM, Kuhlmann C, Trossbach $\mathrm{S}$ et al. The functional role of the second NPXY motif of the LRP1 beta-chain in tissue-type plasminogen activator-mediated activation of N-methyl-D-aspartate receptors. J Biol Chem 2008;283:12004-12013.

24. Williams SE, Ashcom JD, Argraves WS et al. A novel mechanism for controlling the activity of alpha 2-macroglobulin receptor/low density lipoprotein receptor-related protein. Multiple regulatory sites for 39-kDa receptor-associated protein. J Biol Chem 1992;267:9035-9040.

25. Barja F, Coughlin C, Belin D et al. Actin isoform synthesis and mRNA levels in quiescent and proliferating rat aortic smooth muscle cells in vivo and in vitro. Lab Invest 1986;55:226-233.

26. Carmeliet P, Schoonjans L, Kieckens L et al. Physiological consequences of loss of plasminogen activator gene function in mice. Nature 1994;368:419-424.

27. Boucher P, Gotthardt M, Li WP et al. LRP: role in vascular wall integrity and protection from atherosclerosis. Science 2003;300:329-332.

28. Herrmann J, Arias M, Van De Leur E et al. CSRP2, TIMP-1, and SM22alpha promoter fragments direct hepatic stellate cellspecific transgene expression in vitro, but not in vivo. Liver Int 2004;24: 69-79.

29. Puche JE, Lee YA, Jiao J et al. A novel murine model to deplete hepatic stellate cells uncovers their role in amplifying liver damage in mice. Hepatology 2013;57:339-350.

30. Ghiassi-Nejad Z, Friedman SL. Advances in antifibrotic therapy. Expert Rev Gastroenterol Hepatol 2008;2:803-816.

31. Zhang DY, Friedman SL. Fibrosis-dependent mechanisms of hepatocarcinogenesis. Hepatology 2012;56:769-775. 
32. Orth $\mathrm{K}$, Willnow $\mathrm{T}$, Herz J et al. Low density lipoprotein receptor-related protein is necessary for the internalization of both tissue-type plasminogen activator-inhibitor complexes and free tissue-type plasminogen activator. J Biol Chem 1994;269:21117-21122.

33. Kisseleva T, Cong M, Paik $\mathrm{Y}$ et al. Myofibroblasts revert to an inactive phenotype during regression of liver fibrosis. Proc Natl Acad Sci USA 2012;109:9448-9453.

34. Hu K, Yang J, Tanaka S et al. Tissue-type plasminogen activator acts as a cytokine that triggers intracellular signal transduction and induces matrix metalloproteinase-9 gene expression. J Biol Chem 2006;281: 2120-2127.

35. Newton CS, Loukinova E, Mikhailenko I et al. Platelet-derived growth factor receptor-beta (PDGFR-beta) activation promotes its association with the low density lipoprotein receptor-related protein (LRP). Evidence for co-receptor function. J Biol Chem 2005;280:27872-27878.

36. Shi $Y$, Mantuano $E_{\text {, Inoue }} \mathrm{G}$ et al. Ligand binding to LRP1 transactivates Trk receptors by a Src family kinase-dependent pathway. Sci Signal 2009;2:ra18.
37. Roda O, Chiva C, Espuna G et al. A proteomic approach to the identification of new tPA receptors in pancreatic cancer cells. Proteomics 2006;6:S36-S41.

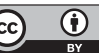

This work is licensed under a Creative Commons Attribution 4.0 International License. The images or other third party material in this article are included in the article's Creative Commons license, unless indicated otherwise in the credit line; if the material is not included under the Creative Commons license, users will need to obtain permission from the license holder to reproduce the material. To view a copy of this license, visit http://creativecommons.org/licenses/by/4.0/ 